\title{
Development of Absorptive Capacity over Time and across Boundaries: the Case of $R \& D$ consortia
}

Omid Omidvar*- Senior Lecturer in Strategic Management, Coventry Business School, Coventry University, Coventr, UK, CV1 5FB

Email:omid.omidvar@coventry.ac.uk

*Corresponding author

Jakob Edler, Professor of Innovation Policy and Strategy - Executive Director, Manchester Institute of Innovation Research (MIoIR), MBS, University of Manchester -Harold Hankins Building- Manchester, UK M13 9PL,

Email: Jakob.edler@mbs.ac.uk

Khaleel Malik- Senior Lecturer- Manchester Institute of Innovation Research (MlolR)- Manchester Business School- University of Manchester- Harold Hankins Building- Manchester- UK- M13 9PL

Email: khaleel.malik@mbs.ac.uk

Article Accepted for publication in Long Range Planning. Please cite this article in press as:

Omidvar, O., Edler, J., Malik, K. Development of absorptive capacity over time and across boundaries: The case of R\&D consortia, Long Range Planning (2017), http://dx.doi.org/10.1016/j.Irp.2017.02.007 


\section{Abstract}

Absorptive capacity (AC) has been identified as the ability of firms to acquire, assimilate, and apply external knowledge, and thus as a pre-condition for learning from external knowledge. However, extant literature has focused on AC as (1) a static and (2) a firm-centred concept. In particular, there is little conceptual framing and empirical evidence of how AC develops over time and across boundaries. Taking R\&D consortia as the unit of analysis and based on insights from three in-depth case studies of collaborative $R \& D$, our contribution is a framework for AC development over time and across inter-organizational, intraorganizational, and practice boundaries at different stages of collaboration in R\&D consortia. Using this framework, we identify a set of mechanisms which enable the development of AC and we discuss the preconditions for these mechanisms. For R\&D managers, our research implies that in order to enhance effectiveness of knowledge transfer and learning in $R \& D$ consortia they need to develop a strategy that (1) supports learning and AC development throughout the whole cycle of the collaboration, not only by focusing on intra-firm capabilities, but in particular by providing flexible interfaces for overcoming a variety of interaction and learning boundaries between heterogeneous R\&D partners, and (2) enables the integration of created and acquired knowledge within the organization once the collaboration is over.

\section{Keywords}

Absorptive Capacity, Boundaries, R\&D consortia, Case study

\section{Introduction}


Defined as the ability to identify, assimilate, and apply external knowledge (Cohen and Levinthal, 1990), absorptive capacity (AC) offers a useful approach to conceptualize and understand how organizations acquire and exploit knowledge - and learn. The concept has inspired a wave of research over the last two decades as authors have explored AC's antecedents (Jansen et al., 2005; Lane and Lubatkin, 1998; Nooteboom et al., 2007), and its consequences for innovation (Hurmelinna-Laukkanen et al., 2007; Tsai, 2001) and competitive advantage (Escribano et al., 2009; Todorova and Durisin, 2007; Zahra and George, 2002) .

However, extant research remains inadequate in explaining and understanding a number of AC aspects. First, most AC research has focused on a single organization or dyadic relations, while there is a dearth of research on how AC develops when multiple organizations are involved and various types of expertise prevail. Although there are a limited number of contributions which have explored AC at the network level (e.g. Müller-Seitz, 2012), no particular theoretical framework has captured the development of AC in those contexts. Second, while there are some conceptual papers that offer theoretical understanding of AC's underlying processes and mechanisms (Lane et al., 2006; Lewin et al., 2011; Todorova and Durisin, 2007; Volberda et al., 2010; Zahra and George, 2002), there is a lack of empirical studies that examine the dynamics of AC. The majority of studies remain limited to applying the concept in a static manner, where AC is usually operationalized as knowledge stock, and widely limited to being an independent variable. Attempting to address this issue, we treat AC also as a dependent variable. While AC remains an enabler for learning, we argue that there is a development of AC itself over time through learning and through specific conditions of learning in consortia. We will show how various mechanisms contribute to the development of AC when more than two organizations - and thus a higher level of heterogeneity - are involved. 
We address the above research gaps by developing a framework to apply and operationalize $\mathrm{AC}$ and learning in the context of three R\&D consortia cases which we define as collaborative R\&D projects involving more than two partners. Following Lane et al.'s (2006) framework, we define consortium-level AC as an ability that develops within the context of R\&D consortia and through three sequential processes of (1) recognizing and understanding potentially valuable new knowledge across partners through exploratory learning, (2) assimilating valuable new knowledge across partners through transformative learning, and (3) using the assimilated knowledge to create new knowledge and commercial outputs through exploitative learning within individual organizations.

R\&D consortia significantly increase the opportunity space for learning through access to new resources and capabilities. They present participating firms with a range of additional challenges. R\&D consortia add heterogeneity in terms of types of organizations and units within organizations and in terms of types of knowledge and professions involved, and thus increase the number of potential complementarities of knowledge assets and capabilities (Feller et al., 2013; Ingham and Mothe, 1998). At the same time, the very heterogeneity that makes $R \& D$ consortia attractive as innovation platforms potentially interferes with the development of common grounds for knowledge exchange, collaborative learning, and knowledge exploitation. Partners with different organizational missions and institutional backgrounds add different types of knowledge expertise, experiences, professional norms and routines and expectations. As such, R\&D consortia involve a higher level of complexity, exposing participants to coordination challenges and potential for conflicts, which in turn may hinder the collaboration performance (Dougherty and Dunne, 2011; Doz et al., 2000; Sydow et al., 2012). Those challenges are not necessarily static, as we may expect that the roles of actors, the nature of interactions, and the opportunities for learning and exploitation change over the life-time of R\&D consortia. 
Against the background of these assumptions, we develop a framework that captures such dynamic heterogeneity and allows us to answer our main research questions, i.e. (1) what constitutes AC in R\&D consortia, (2) how does learning from external knowledge occur in heterogeneous multi partner collaborations and thus (3) how does AC itself develop over time against the background of those different types of boundaries generated by multi-dimensional heterogeneity of R\&D consortia? Our starting premise is that working together and learning under conditions of heterogeneity necessitates the crossing of multi-dimensional boundaries (Carlile, 2002; Hsiao et al., 2012; Oborn and Dawson, 2010). Our framework thus defines and describes different types of boundaries that need to be overcome in order to allow learning to occur. Taking R\&D consortia as our unit of analysis, we analyze the development of mechanisms that support learning and the development of AC across multiple boundaries and throughout the life-cycle of R\&D consortia. As such, our analysis of AC has a focus on the consortium level. However, given that participating organizations contribute to and learn from consortia, inevitably, our analysis of AC encompasses learning at the organizational level.

We contribute to the literature by offering a framework that helps explain the 'microfoundations' (Lewin et al., 2011) of the interaction of AC and learning in heterogeneous settings ( $R \& D$ consortia) during the life time of an $R \& D$ consortium. Our methodological approach to analyze learning and AC in this framework is qualitative. Compared to the quantitative methods that are vastly used in the analysis of AC (Easterby-Smith et al., 2008; Volberda et al., 2010), this allows an in-depth analysis of contexts and their changes over time.

The rest of the paper is organized as follows. We first present the insights from the literature to discuss past $\mathrm{AC}$ research and its potential areas worth of further exploring. We then develop a framework that allows us to respond to our research questions regarding the constitution and development of AC across multiple boundaries in R\&D consortia over time. A 
methodology section outlines how our research was conducted and provides a brief description of the three cases before delving into a more analytical discussion of the findings. The paper concludes with presenting the theoretical and empirical implications of the findings.

\section{Absorptive capacity: concepts and applications in the existing literature}

Owing to more than two decades of research, the AC literature has progressed significantly. Initially, Cohen and Levinthal (1990) conceptualized AC as a capability of a firm to identify, assimilate and apply external knowledge. Research has established that AC enhances interorganizational learning (Lane and Lubatkin, 1998; Lane et al., 2001) and supports reaching out to and collaborating with geographically distant partners (de Jong and Freel, 2010). Consequently, AC was found to contribute to innovations (Ritala and Hurmelinna-Laukkanen, 2013; Rothaermel and Alexandre, 2009; Tsai, 2001) and to reinforce performance and competitive advantage (Escribano et al., 2009; Ferreras-Méndez et al., 2015; Todorova and Durisin, 2007; Zahra and George, 2002).

When focusing on single organizations, AC research has been mainly concerned with the ability to acquire, assimilate and apply knowledge from the general knowledge environment of the firm (absolute $A C$ ) (Kim and Inkpen, 2005; Lane et al., 2001). For dyadic and interorganizational relationships, AC has been conceptualized as the relational ability (Dyer and Singh, 1998) to link different learning environments and institutional contexts in a way that positively supports creating linkages for knowledge exchange and assimilation (relative $A C$ ) (Lane and Lubatkin, 1998). It has been argued that relative AC depends on the similarities between two firms' knowledge bases, organizational structures and compensation policies. The more similarities observed between the dyad partners respecting the aforementioned dimensions, the higher the AC. On this basis, Lane et al. (2001) expanded the formulation of AC to include more contextual elements of cultural compatibility and trust. Re-visiting the 
three dimensions of AC (identification, assimilation, and application), they concluded that while the former two components are relational, and are affected by inter-organizational contexts, the factors that constitute the application dimension of AC are mainly organizational. Table 1 reviews some of the key contributions to AC research indicating how AC is conceptualized and operationalized in those studies. 
Table 1. Key contributions to AC literature

\begin{tabular}{|c|c|c|c|c|c|}
\hline $\begin{array}{l}\text { Key contributions } \\
\text { to } A C\end{array}$ & Type of AC & $\begin{array}{l}\text { Unit of } \\
\text { analysis }\end{array}$ & $\begin{array}{l}\text { Theoretical } \\
\text { determinants of AC }\end{array}$ & $\begin{array}{l}\text { Research } \\
\text { design }\end{array}$ & Description \\
\hline $\begin{array}{l}\text { Cohen and } \\
\text { Levinthal (1990) }\end{array}$ & Absolute & Firm & $\begin{array}{l}\text { Organizational } \\
\text { knowledge base }\end{array}$ & Quantitative & $\begin{array}{l}\text { Prior related knowledge base of the } \\
\text { firm determines its } A C \text { and the path it } \\
\text { takes to develop. AC is motivated by } \\
\text { the presence of knowledge and } \\
\text { spillovers within the industry. }\end{array}$ \\
\hline Szulanski (1996) & Absolute & Firm & $\begin{array}{l}\text { Knowledge stock } \\
\text { (managerial and } \\
\text { technical) }\end{array}$ & Quantitative & $\begin{array}{l}\text { AC of the recipient business unit } \\
\text { determines the success of best } \\
\text { practice transfer from other units } \\
\text { when the knowledge is sticky. }\end{array}$ \\
\hline $\begin{array}{l}\text { Lane and Lubatkin } \\
\text { (1998) }\end{array}$ & Relative & Dyad & $\begin{array}{l}\text { Knowledge base } \\
\text { similarity } \\
\text { Structural similarity } \\
\text { Dominant logics } \\
\text { similarity } \\
\text { Incentive structures }\end{array}$ & Quantitative & $\begin{array}{l}\text { AC depends on the context of the } \\
\text { relationship and the relative aspect of } \\
\text { learning between teacher and student } \\
\text { firm. These characteristics are } \\
\text { relational so AC is a relative concept. }\end{array}$ \\
\hline $\begin{array}{l}\text { Zahra and George } \\
(2002)\end{array}$ & Absolute & Firm & $\begin{array}{l}\text { Potential and realized } \\
\text { AC }\end{array}$ & Conceptual & $\begin{array}{l}\text { AC is a dynamic capability which } \\
\text { builds upon the configuration of } \\
\text { potential and realized AC. The } \\
\text { effectiveness of AC depends on the } \\
\text { capability of firms to strike a balance } \\
\text { between the two. }\end{array}$ \\
\hline Lane et al. (2006) & Absolute & Firm & $\begin{array}{l}\text { Exploratory, } \\
\text { transformative, and } \\
\text { exploitative learning } \\
\text { drive AC }\end{array}$ & Conceptual & $\begin{array}{l}\text { AC consists of three sequential } \\
\text { learning mechanisms of exploratory, } \\
\text { transformative, and exploitative } \\
\text { learning. }\end{array}$ \\
\hline $\begin{array}{l}\text { Nooteboom et al. } \\
(2007)\end{array}$ & Relative & Dyad & $\begin{array}{l}\text { Cognitive proximity } \\
\text { between firms } \\
\text { Patent profile overlaps }\end{array}$ & Quantitative & $\begin{array}{l}\text { AC depends on the cognitive proximity } \\
\text { between two firms. There is reverse } \\
\text { U-shaped relationship between } \\
\text { cognitive proximity and learning. Too } \\
\text { large or too little cognitive distance } \\
\text { impedes learning and innovations. }\end{array}$ \\
\hline $\begin{array}{l}\text { Easterby-Smith et } \\
\text { al. (2008) }\end{array}$ & Absolute & Firm & $\begin{array}{l}\text { Identification, } \\
\text { assimilation and } \\
\text { application of external } \\
\text { knowledge }\end{array}$ & Qualitative & $\begin{array}{l}\text { The paper discusses the role of } \\
\text { episodic, systemic power across } \\
\text { organizational boundaries in } \\
\text { development of AC }\end{array}$ \\
\hline $\begin{array}{l}\text { Vasudeva and } \\
\text { Anand (2011) }\end{array}$ & Relative & $\begin{array}{l}\text { Alliance } \\
\text { portfolio } \\
\text { (network) }\end{array}$ & $\begin{array}{l}\text { Technological diversity } \\
\text { of the portfolio }\end{array}$ & Quantitative & $\begin{array}{l}\text { There is an inverted U-shape } \\
\text { relationship between AC of the } \\
\text { portfolio and knowledge utilization }\end{array}$ \\
\hline $\begin{array}{l}\text { Ceccagnoli and } \\
\text { Jiang (2013) }\end{array}$ & Absolute & Firm & $R \& D$ intensity & Quantitative & $\begin{array}{l}\text { Knowledge supplier transfer } \\
\text { capabilities should be matched by } \\
\text { absorptive capacity of the receiving } \\
\text { firm }\end{array}$ \\
\hline
\end{tabular}


At least two aspects of AC deserve further scrutiny. First, there is a need to explore the role of context. The relative $\mathrm{AC}$ view has been useful in analyzing how inter-organizational context affects AC as it treats each dyad differently. However, analyses of relative AC have mainly relied on quantitative research which is not ideal for capturing the richness of the contexts. Overall, the literature has viewed relative $\mathrm{AC}$ as a function of similarities (or overlaps) between the knowledge bases of the dyad partners, mostly measured through patent base and technological similarities (Hoang and Rothaermel, 2005; Kim and Inkpen, 2005; Schildt et al., 2012).

Secondly, while we know a great deal about the consequences of AC (performance, innovation, learning, competitive advantage), the processes that underlie its development are explored to a lesser extent (Lewin et al., 2011; Volberda et al., 2010). The existing literature conceptualizes and applies AC as an independent variable which contributes to the performance of a firm by supporting innovation, competitive advantage, or knowledge utilization. Easterby-Smith et al. (2008) argue that these studies predominantly fail to explore the inner processes of AC and how they unfold within and between organizations. As such, there have been calls for further analyzing and examining AC as a process, rather than a static capability which is mainly captured by the level of prior knowledge (R\&D intensity, patent base, etc.) (Easterby-Smith et al., 2008; Lane et al., 2006), and as a dependent- as opposed to an independent- variable (Volberda et al., 2010). Although we concur with the assumption that AC is positively related with the benefits reaped out of collaboration, we limit this paper to the preconditions and the underlying mechanisms which form AC in R\&D consortia.

Against this background, the current study further develops two main aspects of AC research: a) to see how AC develops in multilateral collaborations and b) to unpack the processes that underlie AC development itself - in an interplay with learning mechanisms - as a dependent 
variable. To address these issues, we develop a theoretical framework which guides our analysis of AC in the context of R\&D consortia.

\section{Theoretical framework: Collaboration, heterogeneity and time}

Our theoretical framework needs to enable us to answer our research questions, which we restate as follows: (1) what constitutes AC in R\&D consortia, (2) how does learning from external knowledge occur in heterogeneous multi partner collaborations and thus (3) how does AC itself develop over time against the background of different types of boundaries generated by multi-dimensional heterogeneity of R\&D consortia?

Given our interest in understanding the development of AC over time and in heterogeneous contexts, we need to develop a theoretical framework that captures three crucial dimensions of AC; collaboration, heterogeneity, and the dynamics over time. Accordingly, in an attempt to capture these aspects in a coherent framework, we explore the role of collaboration history, the nature and role of boundaries between heterogeneous spaces, and the temporal aspects of AC developing dynamically as a dependent variable.

\section{Prior collaboration experience}

One of the dominant arguments in the extant body of literature is that pre-existing relationships can help organizations to identify, assimilate and internalize knowledge when collaborations are formed (Nam, 2011; Zirulia, 2011). In addition to the learning opportunities offered by collaborations, learning involves interactions between actors who are bounded to their immediate socio-cultural contexts within their organizations. For this reason, some authors have highlighted the significance of partner-specific AC (Dyer and Singh, 1998; Lane and Lubatkin, 1998) in identifying and realizing the opportunities for knowledge absorption and application. It is suggested that pre-existing partnerships can contribute to the development of partner-specific AC (Dyer and Singh 1998, Kim and Inkpen 2005) or to value 
creation in organizations (Anand and Khanna 2000, Kale and Singh 2007). For instance, Sherwood and Covin (2008) have discussed that trust, technology familiarity, alliance experience, and ongoing collaborations within teams determine the success of R\&D alliances. Therefore, we make an assumption that prior collaboration experience is an antecedent of AC and will affect the initial AC level in R\&D consortia.

\section{The significance of boundaries to $A C$}

One core proposition of our framework is that learning and AC development in interorganizational collaboration take place through crossing of different kinds of boundaries. In line with Akkerman and Bakker (2011), we define boundaries as organizational and sociocultural differences that give rise to discontinuities in interaction and action, and in our framework, we distinguish between three forms of boundaries: inter-organizational, intraorganizational, and practice boundaries. While learning and AC in R\&D consortia are mostly associated with inter-organizational boundaries, there are in fact a range of different types boundaries scattered spatially and temporally which are potentially hard to manage. Often, the literature takes the geography of AC for granted, handles the distinction between external and internal rather intuitively, and considers organizational boundaries as the only source of discontinuity crossing of which enables transfer, assimilation, and application of external knowledge (as an exception, see Easterby-Smith et al. (2008a)). However, we argue that the complexity of multi-dimensional boundaries in R\&D consortia needs more than simple transactional management of knowledge exchanges and boundaries. As Levina and Vaast (2005) have shown most impressively, crossing those boundaries relies on the emergence of a 'joint field' - which “... unites agents in their pursuit of common organizational interests while, at the same time, distinguishing them from others who are not engaged in a similar pursuit." (p.337). 
Inter-organizational boundaries: Inter-organizational boundaries have been known both, as a source, and as a barrier for acquisition of 'external' knowledge. In this study, we are particularly interested in these boundaries in two ways. Firstly, inter-organizational boundaries denote the legal boundaries around the firms - i.e. they demarcate the intra from the extra. Formal R\&D consortia bring together actors from different organizations with legally binding contractual arrangements. Secondly, the significance of organizational boundaries is not limited to the legal characteristics of organizations, but also to the differences that encompass the wider sociocultural context within which organizations operate (Heinze and Kuhlmann, 2008). Inter-organizational boundaries may separate a group of organizations who belong to a similar institutional context from others. For instance, the boundary between a university and a company is not only a legal one, but also it denotes a broader difference that prevails across industry and academia as two separate institutional settings with different functionalities, incentive structures, and objectives.

Intra-organizational boundaries: For an organization, the value obtained from external sourcing of knowledge is contingent on how costly it is to cross intra-organizational boundaries and to coordinate internal knowledge (Grigoriou and Rothaermel, 2017). A project team embraces a subset of actors who are officially involved in R\&D consortia. Many organizations use projects to achieve innovations or technological change. However, transfer of knowledge and learning into the wider context of each participating organization can be problematic (Scarbrough et al., 2004; Swan et al., 2010). The temporality of projects makes it difficult for organizations to sustain the knowledge gained from the projects (Prencipe and Tell, 2001).

In R\&D consortia, where partners have limited control over how collaborations are governed and exploited for participating organizations, this problem persists (Li et al., 2012). The knowledge that is generated within $\mathrm{R} \& \mathrm{D}$ consortia can be difficult to transmit to all 
participating organizations as the interfaces between functions within organizations (e.g. R\&D, design, marketing, and manufacturing) influence how knowledge is transferred and utilized for innovations (Adler, 1995; Carlile, 2004; Hauptman and Hirji, 1999; Song et al., 1997). According to Cohen and Levinthal (1990), the interactions among the subunits in an organization are essential for developing cross-functional AC. Therefore, understanding how intra-organizational boundaries work and how they can be crossed is important for analyzing AC.

Practice boundaries: Practice boundaries constitute the third type of boundaries in this study, demarcating differences across practices within the consortia. Santos and Eisenhardt (2005) argue that only focusing on legal boundaries of the firm does not reflect the way organizations interact with their environment, partners, customers, suppliers, etc. Organizations, like their members, belong to multiple communities, networks, alliances, and groups, which make boundaries dynamic and constantly negotiated in regards to professional and disciplinary interests (Hernes 2004; Dougherty and Dunne 2011; Mørk et al. 2012). For long, practice researchers have argued that knowing is situated and vested in communities of practice who may thrive within or across organizations (Lave and Wenger 1991, Boland and Tenkasi 1995, Wenger 1998). The very fact that the practice of a community cannot be accessed by nonmembers is the main element of the boundary. Similarly, people who belong to the same community of practice may find organizational boundaries less of a hurdle for knowledge exchange (Brown and Duguid, 2001).

We use the notion of practice boundaries to refer to the boundary between practices regardless of organizational membership. For instance, while there is a practice boundary between mechanical engineers and material scientists in the same organization, there is no practice boundary between mechanical engineers even if they belong to multiple organizations. In our conceptualization, although we acknowledge that intra-organizational 
boundaries may overlap with practice boundaries, we only refer to practice boundaries when they are external to organizations.

\section{$A C$ development over time}

For AC conceptualization, we build on Lane et al.'s (2006) framework for two reasons: it emphasizes the learning processes, and it understands $\mathrm{AC}$ as a sequential process over time. According to Lane et al. (2006), AC is the “... ability to utilize externally held knowledge through three sequential processes: (1) recognizing and understanding potentially valuable new knowledge outside the firm through exploratory learning, (2) assimilating valuable new knowledge through transformative learning, and (3) using the assimilated knowledge to create new knowledge and commercial outputs through exploitative learning" (p.856). As such, they offer a process view of absorptive capacity which integrates learning with knowledge creation and exploitation.

We combine this definition of AC with relational thinking (Dyer and Singh, 1998; Lane and Lubatkin, 1998; van Burg et al., 2014) to define consortium-level AC as an ability that develops within the context of R\&D consortia and through three sequential processes of (1) recognizing and understanding potentially valuable new knowledge across partners through exploratory learning, (2) assimilating valuable new knowledge across partners through transformative learning, and (3) using the assimilated knowledge to create new knowledge and commercial outputs through exploitative learning within individual organizations.

Exploratory learning process. Exploratory learning predominantly occurs across practice or organizational boundaries where cognitive distances trigger questions and avenues for exploration (Nooteboom, 2006). Across inter-organizational and practice boundaries, there are more opportunities for recognizing new knowledge and experimenting with new ideas provided that mechanisms which can enable crossing the boundaries are present. 
We argue that bridging these boundaries during exploratory learning happens through 'perspective taking' and 'coordination'. Perspective taking refers to understanding and interpreting others' viewpoints, interests, and thoughts through positioning them in relation to one's own knowledge. "This taking of the other into account, in light of a reflexive knowledge of one's own perspective, is the perspective-taking process" (Boland and Tenkasi, 1995 p.362). The importance of perspective taking in knowledge transfer across boundaries is well recognized in the literature. Boland and Tenkasi (1995) found that perspective taking is an indispensable aspect of knowledge-intensive firms with horizontal interactions among various specialized communities of practice. Similarly, examining a multidisciplinary collaboration between cancer specialists, Oborn and Dawson (2010) found perspective taking as a factor deepening the expertise of communities about each other's knowledge.

On the other hand, coordination mechanisms, such as regular meetings, contribute to exploratory learning in $\mathrm{AC}$ as they deal with a set of procedures and means for collaborating in distributed work. They enable collaboration across boundaries even in situations with no consensus (Akkerman and Bakker, 2011) and facilitate knowledge exchange across organizational and practice boundaries (Jansen et al., 2005). Coordination mechanisms are useful for crossing boundaries in two major ways. First, they assist crossing interorganizational boundaries through harmonizing differences and aligning goals. Second, they facilitate crossing practice boundaries through enabling shared language and inducing dialogue between communities. The need for coordination across boundaries increases as the work context becomes innovative and complex (Kogut and Zander, 1992). For instance, by conducting an in-depth case study, Faraj and Xiao (2006) argued that coordination mechanisms are essential to manage distributed expertise in turbulent contexts.

Transformative learning process. The second dimension of AC is transformative learning which links exploratory to exploitative dimensions of $\mathrm{AC}$ and gives rise to the assimilation of 
knowledge. However, while for Lane et al. (2006) transformative learning is limited to combining existing knowledge with new knowledge (Zahra and George, 2002), we argue that transformation includes the mechanisms that give rise to modification, and adaptation of existing structures, processes, routines, and practices in order to generate and accommodate new knowledge. Changing extant processes, resources and routines and continuously establishing new organizational forms enable firms to transition from identifying and acquiring new knowledge through exploration to application of knowledge through exploitation (Rindova and Kotha, 2001; Staber and Sydow, 2002) in the diverse context of consortia which abounds with multiple practice and organizational boundaries. In our formulation, transformation refers to the mechanisms which support change- not necessarily in response to environmental stimuli - as it is in adaptation (Teece et al., 1997) - but to encompass a dynamic, mutual, and interactive process.

Exploitative learning process. The third and final dimension of Lane et al.'s (2006) model is the application of knowledge through exploitative learning in order to create new knowledge and commercial outputs. This aspect of AC relates, on the one hand, to embedding the knowledge within organizations through transferring mechanisms, and, on the other hand, to diversifying its consequents through replication of the acquired knowledge across organizations (Zollo and Winter, 2002).

Transferring refers to the organizational mechanisms employed to make knowledge accessible across time and space (Argote, 2012; Argote and Ingram, 2000). In the context of R\&D consortia, we view transferring as the mechanism for enabling access to collectively generated knowledge across inter-organizational and intra-organizational boundaries. Articulation (Zollo and Winter, 2002) and socialization (Nonaka and Takuchi, 1995) are suggested to be the main mechanisms for transferring knowledge in organizations. When knowledge is articulated, it becomes detached from its social context and can be accessed by 
the wider community. Socialization, on the other hand, relates to the process of transferring (tacit) knowledge through shared experience (Jansen et al., 2005; Nonaka, 1994). Finally, replication of knowledge refers to applying knowledge to areas that fall beyond its original purpose of development (Friesl and Larty, 2013; Lewin et al., 2011). It is through replication, that new applications for the acquired knowledge are identified.

\section{Theoretical framework in a nutshell}

We now have the ingredients for our theoretical framework for analyzing the development of $\mathrm{AC}$ over time and in the context of $\mathrm{R} \& \mathrm{D}$ consortia where heterogeneities abound (Figure 1). First, our theoretical framework explicates that prior history of collaboration is an antecedent for AC and learning. Second, it acknowledges the importance and relevance of boundaries in the heterogeneous context of $R \& D$ consortia and distinguishes between three forms of boundaries: a) practice; b) inter-organizational; and c) intra-organizational. Further, adopting Lane et al.'s (2006) conceptualization of AC, it considers AC as a capability consisting of exploratory, transformative, and exploitative learning processes and combines these phases with the underlying learning mechanisms across boundaries to produce a rich picture to address our research question; that is, what constitutes absorptive capacity and how does it develop in the context of $R \& D$ consortia and against the background of multiple boundaries? Finally, the framework acknowledges that AC is built progressively and past ACs contribute to future ACs. The supporting mechanisms (shown in grey boxes) mutually reinforce learning processes (exploratory, transformative, and exploitative) throughout collaborations which contribute to higher levels of AC in future collaborations. 
Figure 1: Theoretical framework: AC development and learning in consortia

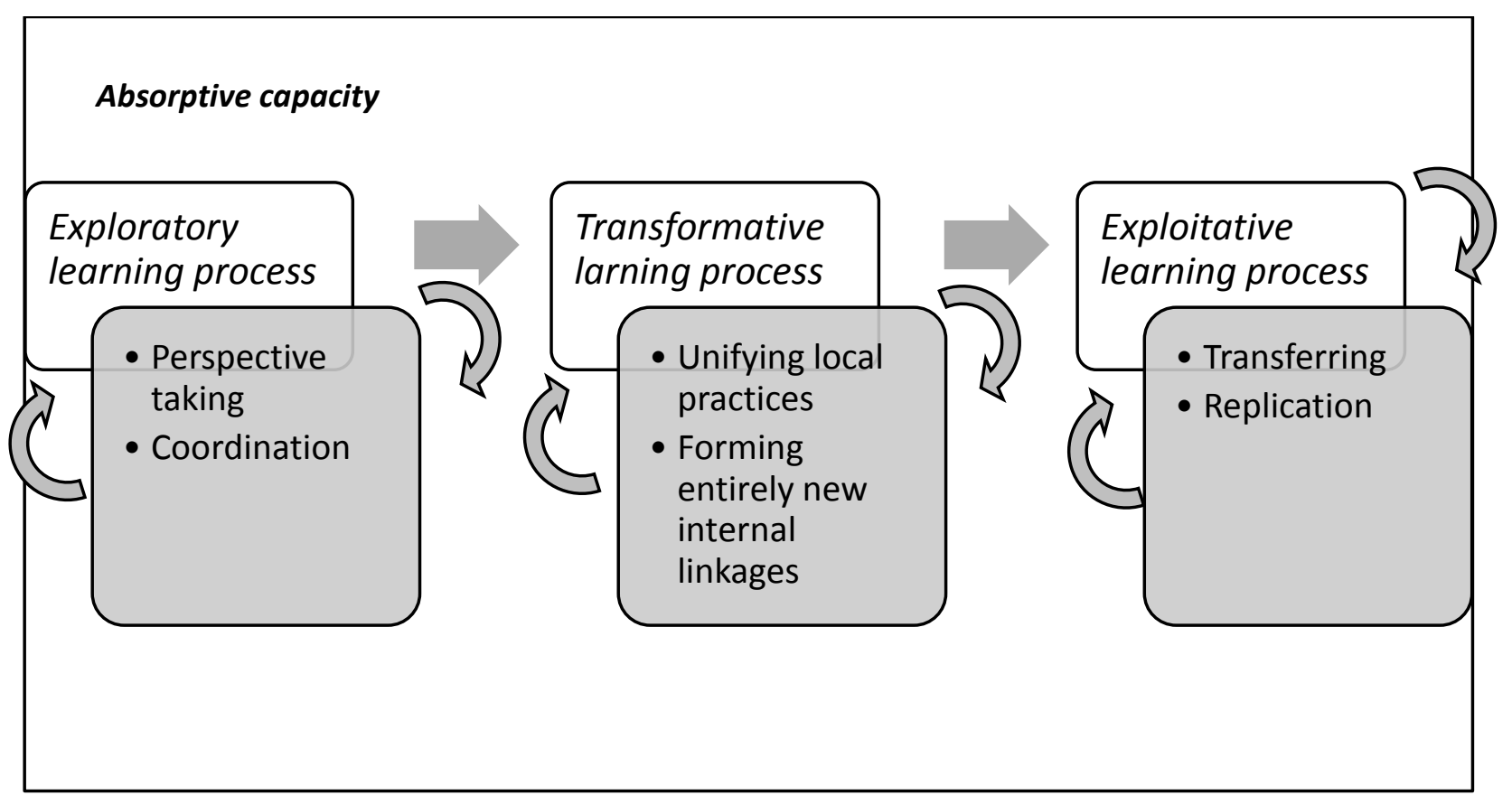




\section{Methodology}

To address our research questions, we applied our framework in a qualitative comparative case study approach, drawing on data gathered from three research consortia. The case study strategy allowed exploration of context and provided a rich description of events revealing the ways processes unfolded throughout collaboration (Eisenhardt, 1989; Yin, 2009). The three case studies analyzed in this research were pseudo named as: HOUSE, ASTHMA, and FLIGHT (see Table 2).

Table 2. Main features of the three cases

\begin{tabular}{|c|c|c|c|}
\hline & HOUSE & ASTHMA & FLIGHT \\
\hline $\begin{array}{l}\text { Collaboration } \\
\text { objective }\end{array}$ & $\begin{array}{l}\text { Analyzing the thermal and } \\
\text { structural features of an } \\
\text { environmentally-friendly } \\
\text { house }\end{array}$ & $\begin{array}{l}\text { Analyzing and categorizing } \\
\text { the biologic profile of } \\
\text { patients with severe asthma }\end{array}$ & $\begin{array}{l}\text { Developing a coating } \\
\text { technology for } \\
\text { lightweight plane } \\
\text { components }\end{array}$ \\
\hline $\begin{array}{l}\text { Past } \\
\text { collaborations }\end{array}$ & $\begin{array}{l}\text { One collaboration among } \\
\text { the research partners in } \\
\text { the past }\end{array}$ & $\begin{array}{l}\text { Ad-hoc collaborations } \\
\text { among some subsets of the } \\
\text { individuals }\end{array}$ & $\begin{array}{l}\text { Previous bilateral } \\
\text { relations }\end{array}$ \\
\hline $\begin{array}{l}\text { Partners } \\
\text { configuration }\end{array}$ & $\begin{array}{l}\text { SMEs, a University, and a } \\
\text { research institute }\end{array}$ & $\begin{array}{l}\text { Large companies, } \\
\text { universities, and research } \\
\text { institutes }\end{array}$ & $\begin{array}{l}\text { Large companies, SME. } \\
\text { and a university }\end{array}$ \\
\hline $\begin{array}{l}\text { Learning } \\
\text { outcomes }\end{array}$ & $\begin{array}{l}\text { Increased understanding } \\
\text { of the product. } \\
\text { Increased collaborative } \\
\text { capabilities. } \\
\text { Increased technical } \\
\text { capability to calculate } \\
\text { embodied carbon. } \\
\text { Increased knowledge of } \\
\text { how to manage a project. } \\
\text { New marketing practices. } \\
\text { Formalizing previously ad- } \\
\text { hoc design and testing } \\
\text { procedures. }\end{array}$ & $\begin{array}{l}\text { Increased understanding of } \\
\text { the mechanisms that affect } \\
\text { the emergence of severe } \\
\text { asthma. } \\
\text { Increased understanding } \\
\text { about interdisciplinarity. } \\
\text { Increased collaborative } \\
\text { capabilities. } \\
\text { Adaptation of new methods, } \\
\text { and models. } \\
\text { Increased collaborative } \\
\text { capability. }\end{array}$ & $\begin{array}{l}\text { Development of a new } \\
\text { coating process. } \\
\text { Building a new high } \\
\text { temperature coating } \\
\text { machine. } \\
\text { Revisiting the testing } \\
\text { procedures and adding } \\
\text { reproducibility test. }\end{array}$ \\
\hline
\end{tabular}

HOUSE: Following on from a collaborative initiative which encourages and funds publicprivate research consortia in the UK, the HOUSE collaboration formed between 6 SMEs, a 
university and a research institute. It aimed at researching the thermal and structural characteristics of a house made of sustainable materials. Achieving this goal necessitated conducting collaborative R\&D efforts across a range of expertise offered by different partners. This research collaboration followed on from a previous collaboration and we understand that a further collaboration was going to start once the HOUSE project was completed.

ASTHMA: ASTHMA was a collaboration aimed at increasing the scientific understanding of asthma disease through gathering and analyzing large scale data sets from patients with chronic asthma. It was a large collaboration and involved large pharmaceutical companies, bio-tech SMEs, and universities. Because of the large size, we only focused on two of the work packages (WP) in this study. The first work package entailed the development of a knowledge management system ${ }^{1}$ and the second one related to developing animal models. We used these two WPs because of their significance in the whole project and the intensive interactions they offered across multiple types of partners (other work-packages were predominantly managed by either universities or companies).

FLIGHT: The FLIGHT collaboration was aimed at enabling the replacement of (heavy) steel bearings with lightweight titanium alloy bearings in aircrafts through developing optimized coating techniques for the latter type. Achieving this goal involved optimization of existing duplex plasma and Physical Vapour Deposition (PVD) treatments and the innovative development of new duplex processes. The collaboration consisted of an aircraft manufacturing company, a bearing manufacturer, a coating SME, and a university.

While research in multi-partner consortia can be carried out to analyze a specific focal firm, or a specific focal dyad, given the objective of this study to unpack the development of AC in the context of $\mathrm{R} \& \mathrm{D}$ consortia, and to analyze the interwoven learning processes that support $\mathrm{AC}$

\footnotetext{
${ }^{1}$ This is different from knowledge management as is broadly understood in the field of management. It is a technical term for conducting large scale data analysis on patient data.
} 
development across multiple levels and boundaries, it is most appropriate to define the R\&D consortia as the unit of analysis.

We deployed semi-structured interviews as the main data collection technique and the overall approach was to interview all the individuals participating in the selected collaborative projects. We conducted 51 interviews (45-90 minutes in duration) with 42 participants across the three cases. Interviews were recorded, transcribed verbatim, and the transcribed interviews were sent back to the respondents for their validations. In addition, documents were analyzed as the supplementary source. These included press releases, meeting minutes and presentations, co-authored publications, and the progress reports of the projects.

To analyze the development of $A C$ in $R \& D$ consortia, we asked about the experience of knowledge sharing, and challenges that the partners faced at different stages of the collaboration, the ways they overcame those challenges, and the conditions enabling those solutions. To capture the development of AC in R\&D consortia, the interview questions were formed in a chronological order by first asking about the initial stages in the development of R\&D consortia, their planning and formation, and their direction taking. Then, a set of questions were asked about the processes and procedures that were developed for collaboration during the next phases of the consortia. Finally, we asked about the learning mechanisms that were developed either towards the end of collaboration or post-completion.

A stage-based method to analyze data was adopted that divided data analysis into two parts. The first stage included developing a rich descriptive account of the cases, which was a thorough presentation of data in a chronological format highlighting the most significant events that affected the learning process in the cases. As a result of this stage, we developed three case reports for each of the analyzed consortia. The second stage of analysis sought developing a more analytical narrative of our findings from the first round of analysis, which were case-specific, into generalizable categories that were applicable across cases based on 
our theoretical framework which both guided and facilitated the interpretation of our observations (Graebner et al., 2012).

As in any conceptual framework, the design of this framework was guided by the research interest, by a set of ontological premises and by existing literature which led us to make certain assumptions about AC and learning and presented us with gaps in our knowledge about AC and learning. However, the framework was not purely deductively constructed, as it was also informed by an initial exploratory empirical step which fed back into further inclusion of literature and an improvement and sharpening of the framework. Although, what is presented here is the theoretical framework in its final shape, as we went through multiple rounds of analysis, we modified the theoretical framework and our interpretation of the data. We started from our broad themes, which related to challenges that the partners faced, and the mechanisms to address them. Then, we grouped the findings into theoretical themes. For a systematic analysis of the data, we used NVivo 8, a qualitative data analysis software package, to code and cross-reference the codes that emerged from the data. The outcome of this stage was the identification of a set of mechanisms that underlie the development of AC across different stages of R\&D consortia.

Finally, to explore the relationship between AC (as a dependent variable) and the identified learning mechanisms that support it, we compared the three cases to see whether and how differences in underlying contextual conditions in cases resulted in varying AC levels. Following this logic, we traced the changes across the three stages in our three R\&D consortia distinguishing between underlying mechanisms on the one hand and the three $\mathrm{AC}$ learning processes (exploratory, transformative, and exploitative) on the other hand.

\section{Findings and analysis}




\section{A process model of $A C$ in the context of $R \& D$ consortia}

\section{Stage 1: the development of exploratory learning process}

Following on from the framework, and based on the collected data, our findings allow us to elaborate on the dimensions of $\mathrm{AC}$ and its underlying mechanisms. The first stage in the development of $\mathrm{AC}$ is exploratory learning which enables recognizing and understanding potentially valuable new knowledge (Lane et al., 2006). We analyzed the nature and role of perspective taking and coordination as mechanisms that underpin exploratory learning particularly during the initial stages of collaboration when practice and organizational boundaries were the strongest. Table 3 depicts representative quotes for this stage.

Table 3. Stage 1: the development of exploratory learning process

\begin{tabular}{|c|c|c|}
\hline \multicolumn{2}{|c|}{ Theoretical constructs } & Representative quotes \\
\hline \multirow[b]{2}{*}{ 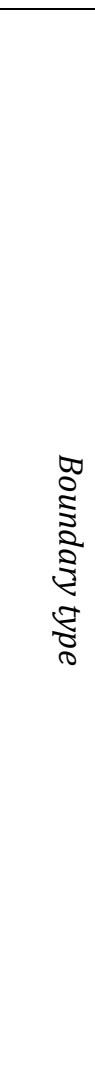 } & $\begin{array}{l}\text { Practice boundaries } \\
\text { (Variances in } \\
\text { technical languages }\end{array}$ & $\begin{array}{l}\text { I come from agriculture where the whole world of architecture and } \\
\text { construction is new to me. Certainly, at first, there were words and } \\
\text { terminology that I did not understand.... (Agricultural engineer-HOUSE, } \\
\text { S1Q12) } \\
\text { I didn't know what data they were collecting, and they didn't really } \\
\text { know initially what sort of data they needed to collect .... (Mechanical } \\
\text { engineer in RESEARCH B-HOUSE, S1Q2) }\end{array}$ \\
\hline & $\begin{array}{l}\text { Inter-organizational } \\
\text { boundaries } \\
\text { (Different } \\
\text { organizational } \\
\text { interests) }\end{array}$ & $\begin{array}{l}\text {...especially at the beginning ... the issue was that we were working with } \\
\text { commercial world and we were researching in an academic world, and } \\
\text { finding the cross-over between the industry way of talking about things, } \\
\text { and the academic methods for communication [was the issue] (Research } \\
\text { head-Architect-HOUSE, S1Q3). } \\
\text { Prior to the symposium [at the early phases of the project], the } \\
\text { companies were secretive and COMPANYE was the most secretive one. } \\
\text { (The industrial work package lead - ASTHMA, S1Q4) } \\
\text {...they (industrial partners) wanted to keep everything until they finish } \\
\text { the project and we were interested in distributing the } \\
\text { information(publications). So, that was the problem in the beginning } \\
\text { (PhD researcher-FLIGHT, S1Q5). }\end{array}$ \\
\hline
\end{tabular}

\footnotetext{
${ }^{2}$ We have used a set of codes within the tables to reference them directly in the text. For simplicity sake, codes are based on the stage and the order by which they appear in the table. For example, S1Q1 refers to the first quote in stage 1 .
} 


\begin{tabular}{|c|c|c|}
\hline \multicolumn{2}{|c|}{ Theoretical constructs } & \multirow{2}{*}{$\begin{array}{l}\text { Representative quotes } \\
\text { [The issue] was eased by [arranging] sub-meetings which helped on issues } \\
\text { and the reports were more concise so there were less intensive readings } \\
\text { (Research head-ARCHITECT- HOUSE, S1Q6) } \\
\text {...if it was something very technical, specifically about the process, then it } \\
\text { meant that we would have more and closer discussion with UNIVERSITY } \\
\text { Crather than involving BEARING and AIRCRAFT, although we would let } \\
\text { them know... (Research scientist A - COATING- FLIGHT, S1Q7) }\end{array}$} \\
\hline \multirow{2}{*}{ 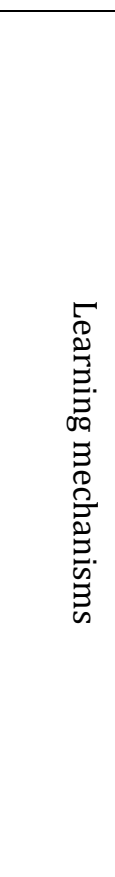 } & Coordination & \\
\hline & Perspective taking & $\begin{array}{l}\text { I [professor of biology] had one person from the computer department } \\
\text { who wanted [a large data set to make the system work]; I brought him } \\
\text { down to my lab and said, "... let's go and do one part of that huge } \\
\text { experiment you asked for. They have been working flat out for a week } \\
\text { with a hundred floss of cells and yet this is a tiny fraction of what you ask } \\
\text { for. You've got to realize that we can't physically do that." (Academic lead, } \\
\text { WPA, ASTHMA S1Q8) } \\
\text { we as academics learned from our commercial partners is just to think } \\
\text { more strictly in timelines, deliverables, etc. (Project coordinator, ASTHMA, } \\
\text { S1Q9). }\end{array}$ \\
\hline
\end{tabular}

Our analysis shows that perspective taking at inter-organizational and practice boundaries contributed to the development of exploratory learning process to recognize and understand externally held knowledge. Through this mechanism, participants 1) made their perspectives clear and accessible to others, and 2) endeavored to understand the perspectives of partners $(\mathrm{S} 1 \mathrm{Q} 8,9,10)$. At practice boundaries, perspective taking pertained to appreciating the complexity of one's own technical language which was crucial for developing meaningful dialogues and to understand new knowledge. Partners gradually started to appreciate the epistemological differences that persisted between practices [e.g. between biologists, and computer scientists, between mechanical engineers and architects, or between surface engineers and aerospace engineers] and made sure that their language was accessible to others partners, and that the different expectations were compatible. Partners from different practices made efforts to familiarize themselves with the technical limitations of others and 
endeavored to address them. It was important to understand what information, data, test results, etc. could be communicated:

... we probably have our own language..., and it is a specialty, what we do, so when we meet with other partners and start talking about how we adapted the coating and how we changed the process, it can be very baffling for them and very difficult to follow. (R\&D head, the coating company, FLIGHT)

In addition, at inter- organizational boundaries we see actors realized and accepted the different work contexts empathizing with the limits that those differences would impose. Across cases, the most significant form of inter-organizational boundary related to the differences between commercial and academic partners. For commercial partners, perspective taking meant to be able to think and behave differently (i.e. to be more open and flexible in their attitudes towards the collaboration) within the consortium compared with their day-to-day activities. For universities, it meant to learn about the restrictions and time pressures within the industry (S1Q10). Academic partners, in particular, tried to empathize (Academic professor, HOUSE) with SMEs, to understand their limited resources and the time horizon that could work for them. At the HOUSE project, a post-doc researcher explained how she learned to appreciate the importance and implication of research findings for commercial companies. She explained that the research outcome depended on the research methodology and commercial partners could potentially lose their competitive edge in the industry because of inferior research outcomes and despite their superior product. This was initially difficult for the academic partner to fully appreciate, but their frequent interactions facilitated this alignment. In ASTHMA, from the academic point of view, perspective taking entailed becoming more receptive to the industrial way of doing things (S1Q9). For commercial partners, in turn, perspective taking meant loosening the routine of following procedures rigorously which would impede interactions. When asked about how industrial partners coped with the academic perspective, the industrial lead of a work package in the ASTHMA project explicated how perspective taking, relaxing the rigorous industrial attitude, and 
flexing the industrial 'way of doing things' can positively affect the success of the collaboration:

... if you apply the hard-nose industry way of doing it, you will probably cause so many arguments that the group will disintegrate. (Industrial lead, WPA, ASTHMA).

The exploratory learning process in FLIGHT relied on perspective taking as recognizing and understanding the specifics of aerospace knowledge (e.g. knowledge about testing adhesion level, and safety measures) could not develop without taking perspective about the sensitivities around safety measures and realizing the reasons behind the rigid attitude towards research and data in the sector. In order to cross the various kinds of boundaries, partners had to put themselves in others' position. The aircraft manufacturer was a completely different organization among the partners, with its large-scale operation and strict safety-driven environment. Therefore, it was important for the partners across the collaboration to take perspectives and to fit their work into the context of the consortium. Initially, it took some time for partner organizations to appreciate the differences that the aircraft manufacturer had given their size and degree of formality compared to other participants. Frequent interactions in addition to hosting the meeting in rotation- which meant that partners could go to the plane manufacturing company-enabled this perspective taking:

... [In the aircraft manufacturer] people very rigidly follow the procedures. They have a particular route to follow and if they want to move off that route, they have to get permission, and it was just helpful to understand that is how they work there and that is how they had to work there, so what we were doing needed to fit in with that... (R\&D head of the coating company)

Like perspective taking, coordination contributed to exploratory learning. Naturally, R\&D consortia abound with various types of technical knowledge that are not easily accessible to all partners. Our findings indicate that coordination complemented perspective taking in the exploratory aspect of AC and consisted of translative and interest alignment mechanisms. In the three cases, while perspective taking across practice boundaries related to appreciating 
the differences across communities, coordination helped with overcoming those differences through simplifying the technical complexity of the professional/technical language or making results accessible to others. For example, in the early phases of the HOUSE project, coordination mechanisms enabled understanding complex knowledge which was, at times, cumbersome for some partners. The structural engineers in HOUSE simplified their language during their presentations in the quarterly meetings, making it comprehensible to the rest of the consortium members. A structural engineer pointed out how they tailored their language (which was used within their practice) at their collective meetings, although they used their specialized language in the meetings that they held separately and among surface engineers. Likewise, in FLIGHT, the differences in languages that participants had were addressed by asking people to simplify, and reduce the jargon. In particular, the aircraft manufacturer was asked to use their special terms in full instead of using abbreviations and were constantly reminded to give full descriptions instead of using acronyms. After a while, they were careful to explain the aspects that they were not sure others would understand (R\&D head, coating company). This point was further corroborated by the $\mathrm{PhD}$ researcher at the university:

I think the fact was that each of us was ready to explain as much detail as was being asked for and provide as much simplification as was needed. So, over a month [since the start of the project], I am pretty sure that everyone was much more on the same line because people actually bothered to explain themselves properly, which was very good. (PhD researcher, FLIGHT)

On some occasions, when the coating company and the university found it difficult for others to grasp details of their findings, they met separately to discuss the findings in detail beforehand. Then, they would reformulate them during the actual meetings; stripping it from all the technical details [R\&D head - coating company] for other consortium partners to better understand.

Next to simplification of language and creating specialized sub-groups to exchange specific technical language, another mechanism of coordination was to focus on the results and what 
they mean, rather than the actual underpinning scientific research. In the HOUSE collaboration, particularly, the work conducted by the research institute was difficult for other partners to comprehend in its details. Therefore, the partners would settle with an understanding of the results instead of having a detailed appreciation of their findings and their models. It was neither necessary nor beneficial to comprehend the detailed technicalities of the work thoroughly. In ASTHMA, an IT platform for analyzing data was developed which enabled collaboration across practice boundaries without the need for each community to fully understand the other. For instance, biologist could input their data without necessarily understanding what happens 'behind the scene'.

Across inter-organizational boundaries, coordination was mainly achieved by providing platforms for creating dialogue between participants from different organizations with different or even diverging organizational interests. In the HOUSE consortium, the physical house enabled direct interactions between various partners so they could discuss their interests and compare and contrast their viewpoints, research interests, and visions for what the house should mean (i.e. a 'research home' vs. a 'show home'). Therefore, in the early phases of the collaboration, coordination enabled exploratory learning (recognizing and understanding external knowledge) without imposing too much pressure on parties to fully engage with technical language and details and by aligning the interests of parties.

\section{Stage 2: the development of transformative learning process}

Transformative learning constitutes the second dimension of $\mathrm{AC}$ according to Lane et al. (2006) and is the ability that links exploratory learning to exploitative learning. Our findings suggest that transformative learning in consortia entailed change, adjustment, and combination of pre-existing routines and processes across various boundaries to assist bridging exploration and exploitation within the consortia. It mainly involved unifying local 


\section{practices through combining the features of the different functional groups or forming}

entirely new internal linkages (Table 4).

Table 4. Stage 2: The development of transformative learning process

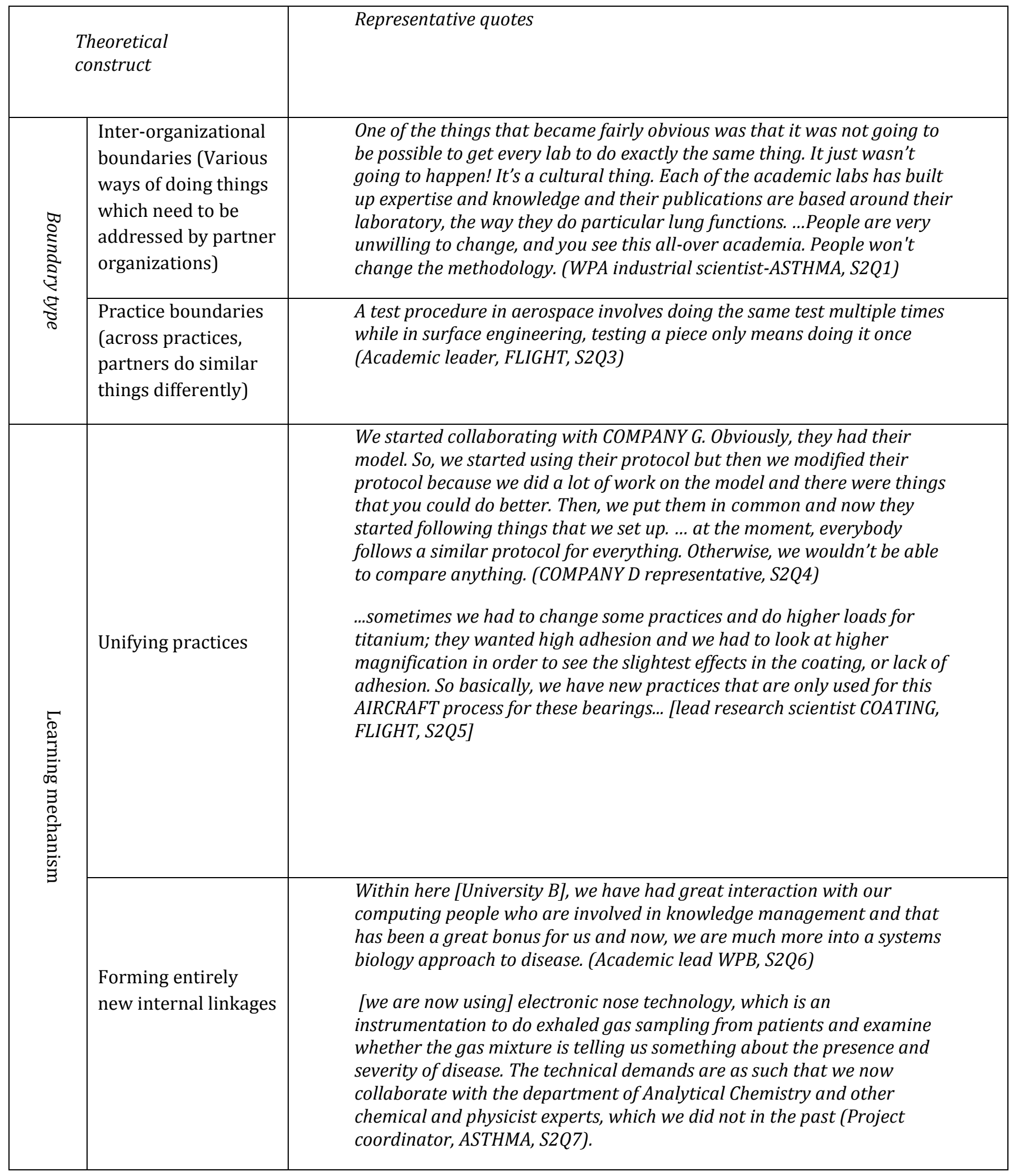


Once partners established an initial understanding of the new knowledge across various boundaries through exploratory learning, they needed to develop mutually agreed research protocols and analytical models for harmonizing their work and making their findings transferable across organizations to be used at later stages. For instance, clinical and nonclinical data were gathered in different ways by partners in ASTHMA as each followed their own Standard Operation Procedures (SOPs) and Case Report Forms (CRFs). This meant that the test results could not be used universally without being sufficiently harmonized across partners. Changing and unifying the local practices contributed to transformative learning as it enabled meaningful and reliable comparison and integration of the results of the initial stage (test results across partners) which were later on used at the exploitative stage to develop a working definition of severe asthma as a basis for treatment development:

...by defining all our methodologies in the project... we now have a commonly agreed standard operating procedures on how to use a questionnaire, how to perform lung function, how to draw blood, etc. The SOPs have been compiled into a big document that changes practices in all our institutes. (Project coordinator, ASTHMA)

Likewise, in FLIGHT, partners modified their test practices to enable consistent application of knowledge across practice and organizational boundaries. Conducting 'reproducibility' test, which investigates how many times a sample can endure load, was necessary for this particular application. This was not a usual practice in academia or among some of the firms, but was crucial for ensuring safety. For academics, it was a completely new concept: "In literature, it is not usually specified how many tests were conducted" (Academic participant). Therefore, because of the requirements of the aircraft manufacturer, the university and the coating company repeatedly tested the bearings under load and measured the average results instead of conducting tests and measuring the results merely once. Close collaboration with the aircraft manufacturing company enabled this change in practice: "we collaborated on something which was going to be used by the partners. What came out of the project was 
immediately used" (Academic participant). The safety measure also required adhesion tests with higher magnification in comparison with routine tests:

...sometimes we had to change some practices and do higher loads for titanium; they wanted high adhesion and we had to look at higher magnification [compared to our routine practice] in order to see the slightest effects in the coating, or lack of adhesion. So basically, we have new practices that are only used for this process for these bearings...

Therefore, unifying practices contributed to the development of transformative learning as it enabled transitioning from identifying and recognizing external knowledge (exploratory learning) into applying it (exploitative learning).

Another mechanism of transformation, particularly in Universities, was to form entirely new linkages. Universities are usually driven by disciplinary focus and are widely criticized for lack of inter-disciplinary work (Huutoniemi, 2010). However, in the context of the consortia, at times, collaboration with other departments and disciplines was essential. In particular, whenever participants found gaps in their knowledge which could not be adequately addressed by their existing expertise, they would form new internal linkages. These new linkages enhanced the transformative learning process because people were forced to move away from their narrow focus and to integrate their knowledge with new knowledge (S2Q6). In the HOUSE consortium, the academic lead of the project initiated a new internal collaboration with the biology department of the university in order to analyze the decay properties of HOUSE. In ASTHMA, the department of computing science at a university was introduced to the project by the respiratory department of the same university; a linkage that was entirely new in the project and only developed because of the need for integrating systems biology approach to the collaboration (S2Q7).

Our findings suggest that forming entirely new internal linkages was more often seen in universities than in firms. In contrast to firms, which usually have a multifunctional structure and do collaborate across departments and functions in order to deliver a product or service, 
in Universities, which are structured around disciplines, there is usually no need (or incentive) for academics to collaborate across their immediate disciplines. Yet the interdisciplinary nature of the examined R\&D consortia, and the focus on satisfying the requirements of industrial partners encouraged universities to form entirely new linkages. Had it not been for the consortia formation, these internal linkages would never have been formed.

\section{Stage 3: the development of exploitative learning process}

The last dimension of $\mathrm{AC}$ is exploitative learning, which relates to the application of knowledge. In the following section, we discuss transferring and replication as the two mechanisms of exploitative learning and discuss their determinants (Table 5).

While change and adaptation were the main features of transformative learning, transferring in our three cases involved communicating and mobilizing knowledge across time and space, with articulation, and socialization as the main mechanisms. Without transferring, the developed knowledge could not have been adequately deployed by individual partner organizations in their wider organizational settings.

Table 5. Stage 3: the development of exploitative learning process

\begin{tabular}{|c|l|l|}
\hline \multicolumn{2}{|c|}{ Theoretical construct } & Representative quotes \\
\hline & $\begin{array}{l}\text { Intra-organizational } \\
\text { boundaries } \\
\text { (Knowledge is held by }\end{array}$ & $\begin{array}{l}\text {...actually, if those involved suddenly disappear I think the company } \\
\text { couldn't carry on with it. It needs us to be around long enough to } \\
\text { transfer it into production, and to have production become skilled at } \\
\text { carrying it out really. If we leave before then, it will be difficult for the } \\
\text { company to carry on. (Research scientist, COATING, FLIGHT, S3Q1) } \\
\text { the project } \\
\text { participant) }\end{array}$ \\
$\begin{array}{l}\text { What we did not want to do was to lose the benefits [after the } \\
\text { completion of the project]. ... [How] can you guarantee that [you] will } \\
\text { continue [exploiting the knowledge internally] (Director, ARCHITECT, } \\
\text { HOUSE, S3Q2). }\end{array}$ \\
\hline
\end{tabular}




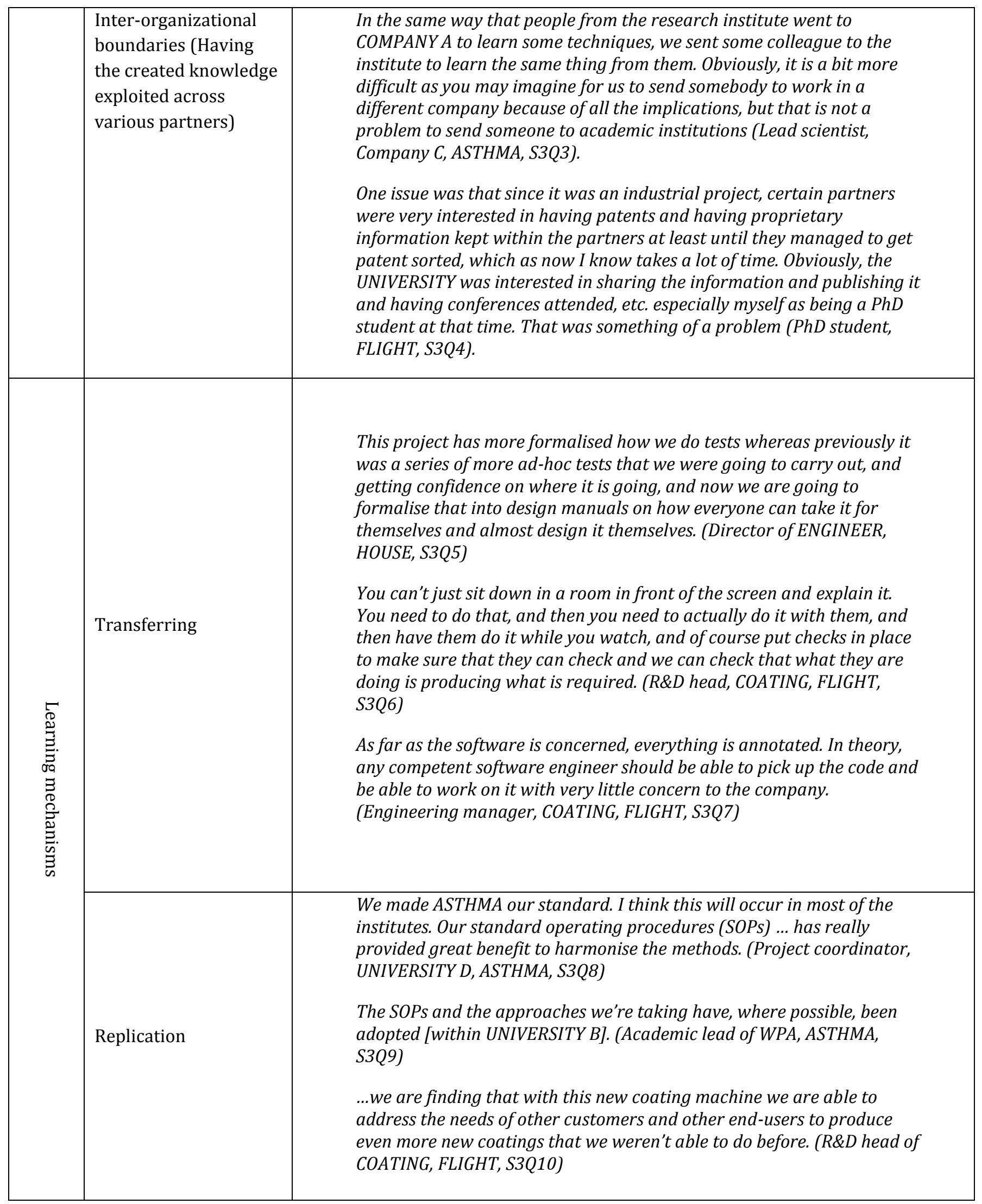


A range of observations within the three case studies suggest that articulation and socialization assisted transfer of knowledge across boundaries and time. Articulation was observed in the forms of documentation (i.e. documenting the obtained knowledge in reports, presentations, published articles, etc.) and formalization (i.e. routinizing the obtained knowledge into instructions and manuals). Formalization through embedding the acquired knowledge into organizational routines was more effective in transferring as it made the knowledge accessible to the wider organizational settings. For instance, developing detailed manuals for structural testing to eliminate ad-hoc procedures in accordance with the testing procedure conducted at HOUSE embedded the knowledge into the wider organizational settings.

Socialization, i.e. the process of sharing (tacit) knowledge through social interactions, was the second main mechanism for knowledge transfer. For instance, in the HOUSE consortium, the design company temporarily recruited the post-doc researcher who was involved in the HOUSE project after the project completion to ensure the availability of knowledge in their company post collaboration. However, lack of socialization in ASTHMA negatively affected knowledge transfer. With the high rate of change in staff, the opportunities for embedding knowledge within the organizations did not form. For example, one of the pharmaceutical companies closed its respiratory site within the UK, assigning the Swedish site to do the research, but none of the UK participants moved into the Swedish site, leaving a gap in the company's knowledge about the research conducted within ASTHMA. However, mobilizing postgraduate and post-doc students enabled transferring knowledge between organizations (space) and throughout the collaboration (time). Finally, in FLIGHT, a researcher was funded to do her PhD in university which facilitated the knowledge circulation process at the final stages of the project. In conditions where the knowledge was particularly sensitive, socialization would happen through intermediary organizations. For example, a post-doc was 
sent from one of the public research institutes to a pharmaceutical company to learn a specific virus modelling. At the same time, another pharmaceutical company needed to learn the same technique, but because of the commercial implications of hosting an employee from a competitor, learning the technique had to be mediated through the public research institute. Therefore, once the post-doc researcher returned from her placement, a post-doc from the learning company joined the research institute temporarily to learn that model and transfer it to their company (intermediation used in combination with mobilizing individuals).

In conjunction with transferring, replication constituted the second aspect of exploitation. Through replication partners applied the knowledge gained from their collaboration into other areas. For instance, the design company (in HOUSE) developed capabilities to calculate embodied carbon for other projects that they commissioned.

...we were taking the knowledge that we learned out of this project and applying it to some other work... and in particular how we calculated the embodied carbon, and, in fact, we have been paid by clients to do that. (Director of the design company)

Similarly, among the commercial partners in FLIGHT, coating and bearing companies were keen to develop a broader technology base out of the collaboration. The coating company aimed at diversifying the exploitation of the technology and applying it to other areas like biomedicine and the bearing firm noted that the technology that had been developed in the FLIGHT collaboration was embedded in their company and is continuously being developed (Technical manager, bearing manufacturer).

Replication was, therefore, critical for exploitative learning as it enabled application of the developed knowledge to domains that were beyond the remit of the project. 


\section{AC as a dependent variable: variances across cases}

Our theoretical framing and the rich data that we gathered from three cases allow us to understand how AC process unfolded across phases. In a next step, we further demonstrate how these different underlying mechanisms translated into AC as a dependent variable. To do so, one needs to explore the differences between the learning mechanisms to establish whether the identified mechanisms resulted in varying ACs across the cases. This will require understanding the differences across contexts, actor constellations and collaboration purposes within the consortia and in different stages. Table 6 presents a comparison across the three cases.

Table 6. Cross-case analysis

\begin{tabular}{|c|c|c|c|}
\hline & & $\begin{array}{l}\text { Mechanisms (to overcome challenges and } \\
\text { achieve goals) }\end{array}$ & Relevant AC level \\
\hline \multirow{3}{*}{ 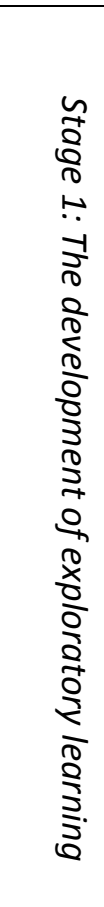 } & HOUSE & $\begin{array}{l}\text { Perspective taking: Empathizing with others' } \\
\text { limitations } \\
\text { Coordination: Translating technical languages } \\
\text { and focusing on results }\end{array}$ & $\begin{array}{l}\text { High level of exploratory learning: } \\
\text { Partners were highly engaged in } \\
\text { experimenting with new ideas, and } \\
\text { acquiring external knowledge. }\end{array}$ \\
\hline & ASTHMA & $\begin{array}{l}\text { Perspective taking: Understanding how } \\
\text { partners work } \\
\text { Coordination: Monthly meetings }\end{array}$ & $\begin{array}{l}\text { Low level of exploratory learning: } \\
\text { Partners were slow to acquire and } \\
\text { understand knowledge from other } \\
\text { partners. }\end{array}$ \\
\hline & FLIGHT & $\begin{array}{l}\text { Perspective taking: Understanding the } \\
\text { rigorous ways of working in aerospace } \\
\text { Coordination: Translating technical languages } \\
\text { and focusing on results }\end{array}$ & $\begin{array}{l}\text { Medium: } \checkmark \checkmark \\
\text { Exploratory learning mainly } \\
\text { developed in dyads instead of the } \\
\text { whole consortium. }\end{array}$ \\
\hline 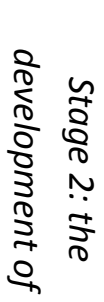 & HOUSE & $\begin{array}{l}\text { Unifying practices: Transforming the standard } \\
\text { test procedures to preserve the appearance. } \\
\text { New linkages: Forming new internal linkages } \\
\text { with biology and physics department within } \\
\text { the university }\end{array}$ & $\begin{array}{l}\text { Medium: } \checkmark \checkmark \\
\text { The transformative dimension } \\
\text { developed within the remit of the } \\
\text { project. }\end{array}$ \\
\hline
\end{tabular}




\begin{tabular}{|c|c|c|c|}
\hline & & $\begin{array}{l}\text { Mechanisms (to overcome challenges and } \\
\text { achieve goals) }\end{array}$ & Relevant AC level \\
\hline & ASTHMA & $\begin{array}{l}\text { Unifying practices: Developing shared SOPs } \\
\text { Forming internal linkages: Forming } \\
\text { collaboration with computer science and } \\
\text { chemistry departments }\end{array}$ & $\begin{array}{l}\text { High: } \checkmark \checkmark \checkmark \\
\text { Transformative learning developed } \\
\text { beyond the remit of the project and } \\
\text { drove setting standards of the } \\
\text { partner companies. }\end{array}$ \\
\hline & FLIGHT & $\begin{array}{l}\text { Unifying practices: Transforming the testing } \\
\text { procedures }\end{array}$ & $\begin{array}{l}\text { Medium: } \checkmark \\
\text { The transformative dimension } \\
\text { developed within the remit of the } \\
\text { project. }\end{array}$ \\
\hline \multirow{3}{*}{ 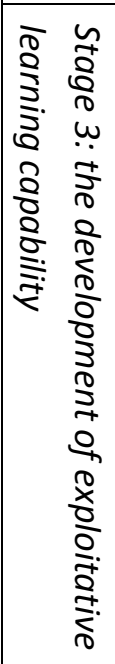 } & HOUSE & $\begin{array}{l}\text { Transferring: Articulation and socialization } \\
\text { were widely used } \\
\text { Replication: Applying the technology to other } \\
\text { problems in the business }\end{array}$ & $\begin{array}{l}\text { High: } \checkmark \checkmark \checkmark \\
\text { All partners were engaged in } \\
\text { embedding the acquired knowledge } \\
\text { into their own organizations. }\end{array}$ \\
\hline & ASTHMA & $\begin{array}{l}\text { Transferring: Socialization and articulation } \\
\text { were moderately used. }\end{array}$ & $\begin{array}{l}\text { Medium: } \checkmark \checkmark \\
\text { Exploitative learning was only } \\
\text { developed in a non-competitive } \\
\text { manner. }\end{array}$ \\
\hline & FLIGHT & $\begin{array}{l}\text { Transferring: Articulation and socialization } \\
\text { were moderately used } \\
\text { Replication: Application of the technology to } \\
\text { other domains was severely restricted }\end{array}$ & $\begin{array}{l}\text { Low: } \checkmark \\
\text { Exploitative learning remained } \\
\text { limited to a very specific application } \\
\text { that AIRCRAFT pursued. }\end{array}$ \\
\hline
\end{tabular}

In line with our theoretically informed expectations, similar mechanisms led to the development of AC across the cases, albeit in different ways. The analysis in this section shows that the three R\&D consortia demonstrated different characteristics in terms of the problems and challenges they faced, the mechanisms they deployed to overcome those challenges and the prior conditions that enabled the development of those mechanisms. Overall, HOUSE and ASTHMA were successful in delivering their goals and achieving the outcomes that they had aimed for at the beginning. However, FLIGHT was only partially successful in delivering the project aim; their very last test failed, although some new coating 
processes were developed. Examining the differences in the development of AC across the cases is particularly illuminating.

At the exploratory learning stage, the three cases presented variances in their initial circumstances. The HOUSE collaboration enjoyed a longstanding history of multi-partner collaboration as well as a significant alignment of organizational interests among multiple partners. These preconditions resulted in streamlined boundary crossing at the outset of the collaboration with high levels of exploratory learning among the partners as they engaged in intensive knowledge exchange, experimenting with new ideas and acquiring knowledge about each other's technical expertise.

Conversely, the ASTHMA partners had no history of prior collaboration, and, therefore, a lowlevel perspective taking and significant hurdles for coordination at the outset. For ASTHMA partners, it took a long time to develop a shared understanding of the project. Therefore, exploratory leaning developed with a slower pace. There was a significant level of new knowledge that required acquisition and circulation, and recognizing and understanding this external knowledge among partners was difficult at the initial stage.

The conditions for FLIGHT were different since it built on prior collaboration between partners in pairs, but there was not a history of collaboration across all parties. This led to some imbalance in perspective taking and coordination across the partners, further exacerbated by the excessive concentration of power at AIRCRAFT as the end-user of the product. In this consortium, perspective taking was limited and mainly unidirectional on part of the partners towards AIRCRAFT. AIRCRAFT only focused on their requirements forcing the collaboration to move to their preferred direction. They hardly engaged in acquiring knowledge from others and showed the lowest levels of perspective taking while continuously "challenging" (Head of the structural stress department, AIRCRAFT) other partners. "Giving way to AIRCRAFT" (R\&D head, BEARING), "addressing their concerns" (R\&D head, COATING), 
and "fulfilling their (AIRCRAFT) requirements" (PhD, UNIVERSITY C) where some of the observations in the context of this collaboration. Thus, although exploratory learning developed, it was not as strong as in the HOUSE case. While partners successfully engaged in identification and understanding of knowledge held by others, this was mainly limited to dyadic relationships.

At the transformative stage, all consortia presented a level of transformation in their practices and new internal linkages were formed especially for the academic partners. However, there were considerable differences in the level and scope of transformative learning developed across the three consortia. The highest level belonged to ASTHMA mainly due to it being an entirely novel collaboration with high levels of practice and organizational variances across partners. Unifying the SOPs and harmonizing the models used in the research consortia was a major task that required a significant amount of change in practices across partners. In changing SOPs, altering the testing models and procedures, and introducing new protocols, a high level of transformative learning was developed which facilitated the transition from exploratory learning (identifying and recognizing new knowledge from partners) to exploitative learning (applying that knowledge internally).

In comparison, HOUSE and FLIGHT demonstrated medium levels of developing transformative learning. The FLIGHT collaboration did not involve any transformation on part of AIRCRAFT as, given the power relations in the consortium; it was mainly down to other partners to change their practices and processes to comply with their requirements. AIRCRAFT mostly remained like a "client" (PhD researcher, FLIGHT). However, transformative learning developed across other partners. For example, the academic partner designed a model which enabled relating the test results in coating to test results in bearings an important ability for linking the exploratory stage (novel knowledge created about coating procedures) to exploitative stage (developing a commercially viable solution for bearings). 
Finally, the case comparison illuminates the conditions and mechanisms conducive to exploitative learning. The HOUSE consortium developed the highest level of exploitative learning. Here, partners successfully engaged in transferring and replication of knowledge across intra-organizational and inter-organizational boundaries. As a result, the exploitative learning developed to a significant level as partners applied the outcome of the project in their respective organizations. For example, the design company fully exploited the knowledge by embedding it into their routines and models while the academic partners extensively used it in their ongoing teaching practices.

In ASTHMA, exploitation was usually sensitive as companies were competitors in the sector. Although the presence of intermediary organizations facilitated exploitative learning across inter-organizational and intra-organizational boundaries, the fact that exploitation relied on the intermediation posed a challenge for developing exploitative learning. Therefore, a medium level of exploitative learning developed because the acquired knowledge was only applied when it was not threatening the competitive position of one partner against others.

In FLIGHT, given the limited flexibility that partners had (due to contractual obligations) in replication of the knowledge in other areas and transferring it within their wider organizational settings, exploitative learning only developed marginally. The application of knowledge remained limited to the specific technology that AIRCRAFT required partners to pursue and there was significant concern that the developed knowledge should remain confined to the project participants; a concern which was reinforced throughout the project.

\section{Discussion and conclusions}

In this study, we asked what constitutes AC, how learning occurs across multiple boundaries, and how AC develops over time. In response, we conceptualized AC in the relational context of collaborations. We then analyzed and examined how AC develops against the background of 
different kinds of boundaries generated by multi-dimensional heterogeneities. We showed that the degree of learning depends on a range of pre-conditions. We further showed empirically that learning mechanisms not only enable learning, but contribute to the ability to learn in the future, i.e. to $\mathrm{AC}$, over time, at different stages of a heterogeneous collaboration and across different kinds of boundaries.

What remains to be established is to provide a synthetic and systematic view of $A C$ mechanisms and their conditions over time which is generalizable across the three R\&D consortia. Below, we discuss the nature of learning mechanisms for different kinds of AC dimensions, as well as their enabling conditions, we have identified, before we conclude with our contribution to the literature and implication for the management of R\&D consortia (Table 7).

Table 7. The mechanisms and preconditions of AC in R\&D consortia

\begin{tabular}{|l|l|l|l|}
\hline AC dimension & Boundaries & Learning mechanisms & Enabling conditions \\
\hline Exploratory & $\begin{array}{l}\text { Inter-organizational } \\
\text { Practice }\end{array}$ & $\begin{array}{l}\text { Perspective taking } \\
\text { Coordination }\end{array}$ & $\begin{array}{l}\text { Active management of } \\
\text { technical languages } \\
\text { Individuals with cross } \\
\text { boundary experience } \\
\text { Sites which enable negotiation } \\
\text { and consolidation of meanings }\end{array}$ \\
\hline Transformative & $\begin{array}{l}\text { Inter-organizational } \\
\text { Practice } \\
\text { Intra-organizational }\end{array}$ & Unifying practices & $\begin{array}{l}\text { Flexible interfaces } \\
\text { Novelty of the collaboration } \\
\text { Collaboration contract that } \\
\text { would allow inclusion of other } \\
\text { participants from an } \\
\text { organization }\end{array}$ \\
& Explos new internal \\
& $\begin{array}{l}\text { Inter-organizational } \\
\text { Intra-organizational }\end{array}$ & $\begin{array}{l}\text { Transferring } \\
\text { Replication }\end{array}$ & $\begin{array}{l}\text { Intermediaries } \\
\text { Dedicated resources for } \\
\text { knowledge exploitation } \\
\text { Planning future collaborations } \\
\text { in the domain } \\
\text { Mobilizing people within and } \\
\text { across organizations }\end{array}$ \\
\hline
\end{tabular}


During exploratory learning, except in situations of repeated collaboration, partners have little familiarity with each other, the scope of research is not fully determined and there are reservations about knowledge sharing. Therefore, initially, the abundance of interorganizational and practice boundaries makes it difficult to exchange knowledge and learn. The main requirement, hence, at this stage is to engage in perspective taking and to deploy interfaces which support coordination across boundaries. This finding particularly aligns with the insights of Ben-Manhem et al. (2013) about the significant role of AC in balancing internal and external changes but it adds to their contribution by explaining the learning mechanisms that link the external to the internal.

Development of transformative learning requires not only harmonizing of collective efforts, but deeper engagement of participating organizations. Therefore, modification of the prevailing practices is critical at this stage. At this phase, partners need to become flexible with respect to their established practices, attitudes and structures so that boundaries start to become more permeable. Moreover, we found that forming new linkages within the participating organizations also supports the spread of knowledge across the entire R\&D consortia. To the authors' knowledge, this aspect of AC is not discussed in the AC literature so far.

Finally, in the exploitative learning phase of $\mathrm{AC}$, individual organizations internalize knowledge within their organizations through transferring and replication. The main requirements for exploitative learning lie in sustaining efforts to apply knowledge within organizations, exposing it to different contexts by encouraging application of knowledge in different areas in organizations and subsequently by embedding it in ongoing routines or in artefacts. Although the importance of application of knowledge or 'realized AC' (Jansen et al., 2005; Zahra and George, 2002) is vastly discussed in the literature, there is less attention paid 
to how these dimensions of AC are practiced in organizations when learning is a result of inter-organizational collaboration.

Although these learning processes develop sequentially, there is a cumulative aspect of AC development over time which deserves further attention. As discussed in our analysis, learning mechanisms underlying $\mathrm{AC}$ are themselves developing dynamically; that is, they change and improve as organizations become more adept in deploying them which then results in increased AC levels. Therefore, past ACs contribute to future ACs as these learning mechanisms become streamlined and efficient. Once learning mechanisms are developed in one collaboration, future collaborations may start with a higher level of AC which will then only further develop. In addition, the cumulative aspect of AC development is also seen where $\mathrm{R} \& \mathrm{D}$ consortia as collective agents learn new knowledge during one time period, and then go on to create further new knowledge in the next time period. This can lead to the creation of new products, processes or services through the convergence of prior and new knowledge.

As for the theoretical discussion of $\mathrm{AC}$, we make two major contributions. First, we conceptualize AC in the highly diverse and multidimensional context of R\&D consortia. AC is deeply entangled with the presence and configuration of boundaries which abound in R\&D consortia with complex organizational arrangement, and heterogonous partners (Dougherty and Dunne, 2011; Omidvar and Kislov, 2015; Santos and Eisenhardt, 2005) where it relies on the partners' ability to orchestrate and enact learning across inter-organizational, intraorganizational, and practice boundaries at the first instance and to embed and replicate that knowledge within their respective organizations at the later stages. Easterby-Smith et al. (2008), acknowledging that AC literature takes boundaries for granted, mainly focused on organizational boundaries from a power dynamics perspective, and they only analyzed single organizations. We complement their approach by investigating the role of intra-organizational 
and practice boundaries in addition to organizational boundaries within R\&D consortia, and by exploring the context of R\&D consortia which consists of multiple partners.

Discussing a set of boundary crossing mechanisms that support $\mathrm{AC}$, and the conditions that support their development, we further contribute to understanding of $\mathrm{AC}$ as a concept that is not purely reliant on the resources and capabilities of a single organization (Cohen and Levinthal, 1990; Lewin et al., 2011; Rothaermel and Alexandre, 2009) or on the attributes of a dyad (Lane and Lubatkin, 1998; Schildt et al., 2012) but on a set of conditions that extend to the broader settings surrounding the interactions. Our comparative analysis of the cases sheds light on how the emergence of a 'shared space' between the collaboration partners can enhance the development of $\mathrm{AC}$, an aspect less discussed in the extant AC research. This links to Levina and Vaast's (2005) finding in their analysis of the implementation of information systems in two different settings that the emergence of 'joint fields' is crucial for successful boundary crossing across organizations. Similarly, the conceptualization of "trading zones" by Kellogg et al. (2006) -in the context of community groups in a web-based advertising company- refers to coordination structures which enables interaction, knowledge exchange, and adaptation when values, norms, interests, and languages differ (Mørk et al., 2012; O'Mahony and Bechky, 2008). Our findings resonate with those of these authors as we demonstrate how the three consortia differ in creating such shared space. We make a contribution towards further understanding AC as a dependent variable (Volberda et al., 2010) by fully unpacking the mechanisms and processes that underlie its development. While many studies make an assumption about what AC is and test the relationship between AC, its antecendents (Burcharth et al., 2014; Lane and Lubatkin, 1998), and consequents (Knockaert et al., 2014; Moilanen et al., 2014), we treat AC both as an enabler and as a dependent variable and explore its underlying mechanisms demonstrating a direct link between AC and its constituting mechanisms. 
Secondly, we contribute to developing a 'process view' to AC' (Lane et al., 2006) in R\&D consortia. We respond to recent calls to conceptualize and examine the temporal aspects of AC, which had not been fully investigated in the literature (Marabelli and Newell, 2014), by treating the temporality of AC seriously, tracing how it evolves across exploratory, transformative, and exploitative phases. Our findings suggest that AC is a temporallyconfigured capability that requires deliberate balancing of learning mechanisms across various stages during an innovation process. This is a significant departure from the existing conceptualizations which consider AC as an atemporal capability (Lewin et al., 2011). As we argued, not only AC is temporally configured but also the significance of its mechanisms varies depending on the stage of knowledge creation and exploitation and the enabling conditions deployed for its development throughout the process.

The study also entails practical implications for consortium managers. First, it suggests that owing to the diversity and heterogeneity of specializations and organizational contexts, understanding the configurations and the dynamics associated with these boundaries is important both for consortium managers and partner organizations. Second, the findings suggest that individual organizations should develop a flexible interface with dedicated boundary spanners to successfully mediate the relationship between consortia and individual organizations (Tortoriello, 2015). This is particularly important for exploratory and transformative stages when partner organizations modify their pre-existing structures and processes in order to comply with the consortium requirements. Finally, in order to exploit the full benefits of R\&D collaborations, it is imperative for organizations to actively support the intra-organizational transfer of knowledge and new practices.

We acknowledge the limitations of our research. The first issue here is the limit to generalizability of findings form case study work. However, we do not claim that our findings are generalizable for all collaborative situations, or that they constitute general causalities 
across industrial R\&D contexts. Rather, we looked at three clearly defined and described contexts of cooperation. This means that we can identify indications for the importance of different context conditions for the mechanisms we are interested in, and, second, that we can find common features across different contexts. While this brings us closer to theoretical generalization (Yin 2003), we do not claim theory building here, but we believe that our approach has assisted us to extend the theory by focusing particular attention on concepts that do not seem to have adequate theoretical referents in the existing literature. Secondly, we are aware that we focus on consortia as unit of analysis and did not take into consideration whether and how different organizations play different roles in building the consortium-level AC. Future research should address these aspects.

\section{References}

Adler, P.S., 1995. Interdepartmental interdependence and coordination: The case of the design/manufacturing interface. Organization Science 6 (2), 147-167.

Akkerman, S.F., Bakker, A., 2011. Boundary crossing and boundary objects. Review of Educational Research 81 (2), 132-169.

Argote, L., 2012. Organizational learning: Creating, retaining and transferring knowledge. Springer.

Argote, L., Ingram, P., 2000. Knowledge transfer: A basis for competitive advantage in firms. Organizational Behavior and Human Decision Processes 82 (1), 150-169.

Ben-Menahem, S.M., Kwee, Z., Volberda, H.W., Van Den Bosch, F.a.J., 2013. Strategic renewal over time: The enabling role of potential absorptive capacity in aligning internal and external rates of change. Long range planning 46 (3), 216-235.

Brown, J.S., Duguid, P., 2001. Knowledge and organization: A social-practice perspective. Organization Science 12 (2), 198-213.

Burcharth, A.L.L.D.A., Lettl, C., Ulhøi, J.P., 2014. Extending organizational antecedents of absorptive capacity: Organizational characteristics that encourage experimentation. Technological Forecasting and Social Change.

Carlile, P.R., 2002. A pragmatic view of knowledge and boundaries: Boundary objects in new product development. Organization Science 13 (4), 442-455.

Carlile, P.R., 2004. Transferring, translating, and transforming: An integrative framework for managing knowledge across boundaries. Organization Science 15 (5), 555-568.

Ceccagnoli, M., Jiang, L., 2013. The cost of integrating external technologies: Supply and demand drivers of value creation in the markets for technology. Strategic Management Journal 34 (4), 404-425. 
Cohen, W.M., Levinthal, D.A., 1990. Absorptive capacity: A new perspective on learning and innovation. Administrative Science Quarterly 35 (1), 128-152.

De Jong, J.P.J., Freel, M., 2010. Absorptive capacity and the reach of collaboration in high technology small firms. Research Policy 39 (1), 47-54.

Dougherty, D., Dunne, D.D., 2011. Organizing ecologies of complex innovation. Organization Science 22 (5), 1214-1223.

Doz, Y.L., Olk, P.M., Ring, P.S., 2000. Formation processes of r\&d consortia: Which path to take? Where does it lead? Strategic Management Journal 21 (3), 239-266.

Dyer, J.H., Singh, H., 1998. The relational view: Cooperative strategy and sources of interorganizational competitive advantage. The Academy of Management Review 23 (4), 660-679.

Easterby-Smith, M., Graça, M., Antonacopoulou, E., Ferdinand, J., 2008. Absorptive capacity: A process perspective. Management Learning 39 (5), 483-501.

Eisenhardt, K.M., 1989. Building theories from case study research. The Academy of Management Review 14 (4), 532-550.

Escribano, A., Fosfuri, A., Tribó, J.A., 2009. Managing external knowledge flows: The moderating role of absorptive capacity. Research Policy 38 (1), 96-105.

Feller, J., Parhankangas, A., Smeds, R., Jaatinen, M., 2013. How companies learn to collaborate: Emergence of improved inter-organizational processes in r\&d alliances. Organization Studies 34 (3), 313-343.

Ferreras-Méndez, J.L., Newell, S., Fernández-Mesa, A., Alegre, J., 2015. Depth and breadth of external knowledge search and performance: The mediating role of absorptive capacity. Industrial Marketing Management 47, 86-97.

Friesl, M., Larty, J., 2013. Replication of routines in organizations: Existing literature and new perspectives. International Journal of Management Reviews 15 (1), 106-122.

Graebner, M.E., Martin, J.A., Roundy, P.T., 2012. Qualitative data: Cooking without a recipe. Strategic Organization 10 (3), 276-284.

Grigoriou, K., Rothaermel, F.T., 2017. Organizing for knowledge generation: Internal knowledge networks and the contingent effect of external knowledge sourcing. Strategic Management Journal 38 (2), 395-414.

Hauptman, O., Hirji, K.K., 1999. Managing integration and coordination in cross-functional teams: An international study of concurrent engineering product development. R\&D Management 29 (2), 179192.

Heinze, T., Kuhlmann, S., 2008. Across institutional boundaries?: Research collaboration in german public sector nanoscience. Research Policy 37 (5), 888-899.

Hoang, H., Rothaermel, F.T., 2005. The effect of general and partner-specific alliance experience on joint r\&d project performance. Academy of Management Journal 48 (2), 332-345.

Hsiao, R.-L., Tsai, D.-H., Lee, C.-F., 2012. Collaborative knowing: The adaptive nature of cross-boundary spanning. Journal of Management Studies 49 (3), 463-491. 
Hurmelinna-Laukkanen, P., Blomqvist, K., Camarinha-Matos, L., Afsarmanesh, H., Novais, P., Analide, C., 2007. Fostering r\&d collaboration - the interplay of trust, appropriability and absorptive capacity establishing the foundation of collaborative networks. Springer Boston, pp. 15-22.

Huutoniemi, K., 2010. Evaluating interdisciplinary research. Oxford: Oxford University Press.

Ingham, M., Mothe, C., 1998. How to learn in r\&d partnerships? R\&D Management 28 (4), 249-261.

Jansen, J.J.P., Van Den Bosch, F.a.J., Volberda, H.W., 2005. Managing potential and realized absorptive capacity: How do organizational antecedents matter? Academy of Management Journal.

Kellogg, K.C., Orlikowski, W.J., Yates, J., 2006. Life in the trading zone: Structuring coordination across boundaries in postbureaucratic organizations. Organization Science 17 (1), 22-44.

Kim, C.-S., Inkpen, A.C., 2005. Cross-border r\&d alliances, absorptive capacity and technology learning. Journal of International Management 11 (3), 313-329.

Knockaert, M., Spithoven, A., Clarysse, B., 2014. The impact of technology intermediaries on firm cognitive capacity additionality. Technological Forecasting and Social Change 81 (1), 376-387.

Lane, P.J., Koka, B.R., Pathak, S., 2006. The reification of absorptive capacity: A critical review and rejuvenation of the construct. Academy of Management Review 31 (4), 833-863.

Lane, P.J., Lubatkin, M., 1998. Relative absorptive capacity and interorganizational learning. Strategic Management Journal 19, 461-477.

Lane, P.J., Salk, J.E., Lyles, M.A., 2001. Absorptive capacity, learning, and performance in international joint ventures. Strategic Management Journal 22 (12), 1139-1161.

Levina, N., Vaast, E., 2005. The emergence of boundary spanning competence in practice: Implications for implementation and use of information systems. MIS Quarterly 29 (2), 335-363.

Lewin, A.Y., Massini, S., Peeters, C., 2011. Microfoundations of internal and external absorptive capacity routines. Organization Science 22 (1), 81-98.

Li, D., Eden, L., Hitt, M.A., Ireland, R.D., Garrett, R.P., 2012. Governance in multilateral r\&d alliances. Organization Science 23 (4), 1191-1210.

Marabelli, M., Newell, S., 2014. Knowing, power and materiality: A critical review and reconceptualization of absorptive capacity. International Journal of Management Reviews, n/a-n/a.

Moilanen, M., Østbye, S., Woll, K., 2014. Non-r\&d smes: External knowledge, absorptive capacity and product innovation. Small Business Economics.

Mørk, B.E., Hoholm, T., Maaninen-Olsson, E., Aanestad, M., 2012. Changing practice through boundary organizing: A case from medical r\&d. Human Relations 65 (2), 263-288.

Müller-Seitz, G., 2012. Absorptive and desorptive capacity-related practices at the network level - the case of sematech. R\&D Management 42 (1), 90-99.

Nam, K.-M., 2011. Learning through the international joint venture: Lessons from the experience of china's automotive sector. Industrial and Corporate Change 20 (3), 855-907.

Nonaka, I., 1994. A dynamic theory of organizational knowledge creation. Organization Science 5 (1), 14-37. 
Nooteboom, B., 2006. Cognitive distance in and between cop's and firms: Where do exploitation and exploration take place, and how are they connected?, Durham.

Nooteboom, B., Van Haverbeke, W., Duysters, G., Gilsing, V., Van Den Oord, A., 2007. Optimal cognitive distance and absorptive capacity. Research Policy 36 (7), 1016-1034.

O'mahony, S., Bechky, B.A., 2008. Boundary organizations: Enabling collaboration among unexpected allies. Administrative Science Quarterly 53 (3), 422-459.

Oborn, E., Dawson, S., 2010. Learning across communities of practice: An examination of multidisciplinary work. British Journal of Management 21 (4), 843-858.

Omidvar, O., Kislov, R., 2015. R\&d consortia as boundary organisations: Misalignment and asymmetry of boundary management. International Journal of Innovation Management.

Prencipe, A., Tell, F., 2001. Inter-project learning: Processes and outcomes of knowledge codification in project-based firms. Research Policy 30 (9), 1373-1394.

Rindova, V.P., Kotha, S., 2001. Continuous "morphing": Competing through dynamic capabilities, form, and function. The Academy of Management Journal 44 (6), 1263-1280.

Ritala, P., Hurmelinna-Laukkanen, P., 2013. Incremental and radical innovation in coopetition-the role of absorptive capacity and appropriability. Journal of Product Innovation Management 30 (1), 154169.

Rothaermel, F.T., Alexandre, M.T., 2009. Ambidexterity in technology sourcing: The moderating role of absorptive capacity. Organization Science 20 (4), 759-780.

Santos, F.M., Eisenhardt, K.M., 2005. Organizational boundaries and theories of organization. Organization Science 16 (5), 491-508.

Scarbrough, H., Swan, J., Laurent, S.P., Bresnen, M., Edelman, L., Newell, S., 2004. Project-based learning and the role of learning boundaries. Organization Studies 25 (9), 1579-1600.

Schildt, H., Keil, T., Maula, M., 2012. The temporal effects of relative and firm-level absorptive capacity on interorganizational learning. Strategic Management Journal 33 (10), 1154-1173.

Sherwood, A.L., Covin, J.G., 2008. Knowledge acquisition in university-industry alliances: An empirical investigation from a learning theory perspective. Journal of Product Innovation Management 25 (2), 162-179.

Song, X.M., Montoya-Weiss, M.M., Schmidt, J.B., 1997. Antecedents and consequences of crossfunctional cooperation: A comparison of $\mathrm{r} \& \mathrm{~d}$, manufacturing, and marketing perspectives. Journal of Product Innovation Management 14 (1), 35-47.

Staber, U., Sydow, J., 2002. Organizational adaptive capacity: A structuration perspective. Journal of Management Inquiry 11 (4), 408-424.

Swan, J., Scarbrough, H., Newell, S., 2010. Why don't (or do) organizations learn from projects? Management Learning 41 (3), 325-344.

Sydow, J., Windeler, A., Schubert, C., Möllering, G., 2012. Organizing r\&d consortia for path creation and extension: The case of semiconductor manufacturing technologies. Organization Studies 33 (7), 907936.

Teece, D.J., Pisano, G., Shuen, A., 1997. Dynamic capabilities and strategic management. Strategic Management Journal 18 (7), 509-533. 
Todorova, G., Durisin, B., 2007. Absorptive capacity: Valuing a reconceptualization. Academy of Management Review 32 (3), 774-786.

Tortoriello, M., 2015. The social underpinnings of absorptive capacity: The moderating effects of structural holes on innovation generation based on external knowledge. Strategic Management Journal $36(4), 586-597$.

Tsai, W., 2001. Knowledge transfer in intraorganizational networks: Effects of network position and absorptive capacity on business unit innovation and performance. The Academy of Management Journal 44 (5), 996-1004.

Van Burg, E., Berends, H., Van Raaij, E.M., 2014. Framing and interorganizational knowledge transfer: A process study of collaborative innovation in the aircraft industry. Journal of Management Studies 51 (3), 349-378.

Vasudeva, G., Anand, J., 2011. Unpacking absorptive capacity: A study of knowledge utilization from alliance portfolios. Academy of Management Journal 54 (3), 611-623.

Volberda, H.W., Foss, N.J., Lyles, M.A., 2010. Absorbing the concept of absorptive capacity: How to realize its potential in the organization field. Organization Science 21 (4), 931-951.

Yin, R.K., 2009. Cases study research: Design and methods 4th ed. Sage, London.

Zahra, S., George, G., 2002. Absorptive capacity: A review, reconceptualization, and extension. Academy of Management Review 27 (2), 185-203.

Zirulia, L., 2011. The role of spillovers in r\&d network formation. Economics of Innovation and New Technology 21 (1), 83-105.

Zollo, M., Winter, S.G., 2002. Deliberate learning and the evolution of dynamic capabilities. Organization Science 13 (3), 339-351. 
